\title{
Maryam Nourzaei, Carina Jahani, Erik Anonby, Abbas Ali Ahangar. Koroshi. A Corpus-based Grammatical Description
}

\section{Chams Bernard}

\section{(2) OpenEdition Journals}

Édition électronique

URL : http://journals.openedition.org/abstractairanica/43087

DOI : 10.4000/abstractairanica.43087

ISBN : 1961-960X

ISSN : 1961-960X

Éditeur :

CNRS (UMR 7528 Mondes iraniens et indiens), Éditions de l'IFRI

\section{Référence électronique}

Chams Bernard, « Maryam Nourzaei, Carina Jahani, Erik Anonby, Abbas Ali Ahangar. Koroshi. A Corpusbased Grammatical Description », Abstracta Iranica [En ligne], Volume 37-38-39 | 2018, document 2, mis en ligne le 30 décembre 2018, consulté le 27 septembre 2020. URL : http://journals.openedition.org/ abstractairanica/43087 ; DOI : https://doi.org/10.4000/abstractairanica.43087

Ce document a été généré automatiquement le 27 septembre 2020

Tous droits réservés 


\title{
Maryam Nourzaei, Carina Jahani, Erik Anonby, Abbas Ali Ahangar. Koroshi. A Corpus-based Grammatical Description
}

\author{
Chams Bernard
}

\section{RÉFÉRENCE}

Maryam Nourzaei, Carina Jahani, Erik Anonby, Abbas Ali Ahangar. Koroshi. A Corpusbased Grammatical Description. Uppsala, Acta Universitatis Upsaliensis, 2015, 315p. (Studia Iranica Upsaliensia 13).

1 L'ouvrage ci-présent est une étude de la langue koroshi, apparentée aux langues du sud du Baloutchistan (« [...] Koroshi can be described as a distinct sub-group within the Balochi macro-language, although it shares many features with southern dialects of Balochi » p. 25).

2 Les remerciements, pp. 15 et 16, témoignent de la quantité de collaborateurs qui a rendu cette étude possible. L'introduction, pp. 17-20, décrit le processus de recherche mené à bien par les auteurs, le corpus obtenu par ceux-ci, et résume le reste du livre. La partie 2 (pp. 21-24) traite du peuple korosh, leur distribution géographique, leurs origines, leur culture et leur rapport à leur langue. La partie suivante, pp. 25-120, est une étude de la langue koroshi traitant de la phonologie (pp. 25-28), de la morphologie (pp. 28-38), de la construction avec ezāfe (pp. 39-41), des adjectifs, adverbes, puis adpositions (pp. 41-46), des pronoms (de façon particulièrement développée, pp. 46-62), des numéros et des classificateurs (pp. 62-64). Les pages 66 à 98 décrivent le verbe et le système verbal en koroshi. Les pages 98 à 121 discutent des faits de syntaxe, notamment la coordination (pp. 101-104) et la subordination (pp. 104-120). 
3 Les pages 123 à 290 contiennent sept textes koroshi, principalement des contes, mais aussi les souvenirs d'un des informateurs, et un texte sur le tissage. Le corpus est assez grand, avec gloses et traduction. Enfin, le glossaire (pp. 291-312) reprend, traduits en anglais, les mots koroshi utilisés dans le reste de l'ouvrage.

4 Le livre, fait très appréciable, est également fourni avec un cd-rom, contenant des photographies en couleur, ainsi que les enregistrements des sept textes du corpus. Ceci rend l'étude ci-présente plus vivante encore et est une excellente initiative des auteurs.

5 Ce livre est une référence indispensable pour qui s'intéresse au koroshi, et plus généralement aux Baloutches et au Baloutchistan, et aux langues iraniennes modernes.

\section{AUTEURS}

\section{CHAMS BERNARD}

Paris 